\title{
SERVICE CONVENIENCE UPT RUMAH SAKIT MATA MASYARAKAT JAWA TIMUR
}

\author{
Selly Apriyanti, Nyoman Anita Damayanti \\ Departemen Administrasi dan Kebijakan Kesehatan \\ Fakultas Kesehatan Masyarakat Universitas Airlangga \\ Kampus C Unair Mulyorejo \\ Alamat Korespondensi: \\ Selly Apriyanti \\ Email: sellyaprr@hotmail.com
}

\begin{abstract}
Patient satisfaction is one of the most important thing for a hospital because patient satisfaction is one of indicators which is assessed in hospital minimum service standards. One of the factors that can affect patient satisfaction on a service is service convenience, which means patient perception about time and effort related to purchase or use of services offered. The aim of this research was to analyze service convenience of UPT RSMM Jawa Timur which consists of decision convenience, access convenience, transaction convenience, benefit convenience, and postbenefit convenience. This research was a descriptive research with cross sectional design. The sample was calculated by Lemeshow formula (1991), that is equal to 72 patients and taken by accidental sampling. Data were collected through questionnaires submitted through interviews. The results showed that the majority of respondents have good assessment of the decision convenience, benefit convenience, and postbenefit convenience. However, it has poor assessment of access convenience and transaction convenience. Therefore, UPT RSMM Jawa Timur needs to pay attention to access convenience and transaction convenience by maximizing the use of Electronic Data Capture machine in conducting payment transactions, adding signboard or billboard placed in strategic place to give information about location of UPT RSMM Jawa Timur, and consider to provide a home stay facility for out-of-town patients.
\end{abstract}

Keywords: patient satisfaction, service convenience.

\begin{abstract}
ABSTRAK
Kepuasan pasien merupakan hal yang sangat penting bagi sebuah rumah sakit karena kepuasan pasien merupakan salah satu indikator yang dinilai dalam standar pelayanan minimal rumah sakit. Salah satu faktor yang dapat memengaruhi kepuasan pasien terhadap pelayanan jasa adalah service convenience, yaitu persepsi pasien mengenai waktu dan usaha yang berkaitan dengan pembelian atau pemakaian jasa yang ditawarkan. Tujuan penelitian ini adalah menganalisis service convenience di UPT RSMM Jawa Timur yang meliputi decision convenience, access convenience, transaction convenience, benefit convenience, dan postbenefit convenience. Penelitian ini merupakan penelitian deskriptif dengan desain cross sectional. Besar sampel dihitung dengan menggunakan rumus Lemeshow (1991), yaitu sebesar 72 pasien dan diambil dengan cara accidental sampling. Pengambilan data dilakukan dengan kuesioner yang disampaikan melalui wawancara. Hasil penelitian menunjukkan mayoritas responden memiliki penilaian yang baik terhadap decision convenience, benefit convenience, dan postbenefit convenience. Di lain sisi, mayoritas responden memiliki penilaian yang kurang baik terhadap access convenience dan transaction convenience. Oleh karena itu, UPT RSMM Jawa Timur perlu memperhatikan access convenience dan transaction convenience dengan cara memaksimalkan penggunaan mesin Electronic Data Capture dalam melakukan transaksi pembayaran, menambahkan papan petunjuk atau baliho yang diletakkan di tempat strategis guna memberikan informasi mengenai
\end{abstract}


letak UPT RSMM Jawa Timur, dan mempertimbangkan untuk mengadakan fasilitas rumah singgah bagi pasien luar kota.

Kata kunci: kepuasan pasien, service convenience

\section{PENDAHULUAN}

Kesehatan merupakan hak asasi setiap manusia. Sejalan dengan hal tersebut, pemerintah selalu meningkatkan kinerjanya untuk meningkatkan derajat kesehatan masyarakat dalam memperoleh akses atas sumber daya di bidang kesehatan sehingga masyarakat dapat memperoleh pelayanan kesehatan yang aman, bermutu, dan terjangkau (Undang-Undang Republik Indonesia No. 36 Tahun 2009 Tentang Kesehatan). Untuk mewujudkan hal tersebut, dalam Undang-Undang Republik Indonesia No. 40 Tahun 2004 Tentang Sistem Jaminan Sosial Nasional (SJSN) disebutkan pemerintah mengamanatkan bahwa setiap orang berhak atas jaminan sosial untuk dapat memenuhi kebutuhan dasar hidup yang layak dan meningkatkan martabatnya menuju terwujudnya masyarakat Indonesia yang sejahtera, adil, dan makmur.

Program JKN yang dikembangkan di Indonesia merupakan bagian dari Sistem Jaminan Sosial Nasional yang diselenggarakan melalui mekanisme asuransi sosial. Adapun alur pelayanan bagi peserta program JKN adalah dengan diberlakukannya sistem rujukan pelayanan kesehatan berjenjang yang dilaksanakan secara berjenjang sesuai kebutuhan medis.

Rujukan berjenjang dimulai dari pelayanan kesehatan tingkat pertama oleh FKTP kemudian jika diperlukan pelayanan lanjutan oleh spesialis, maka pasien dapat dirujuk ke FKRTL. Pelayanan kesehatan tingkat kedua di FKRTL tersebut hanya dapat diberikan atas rujukan dari FKTP dan pelayanan kesehatan tingkat ketiga di faskes tersier hanya dapat diberikan atas rujukan dari faskes sekunder dan faskes primer.

Sejak diberlakukannya program JKN pada tahun 2014, masih banyak permasalahan yang muncul. Salah satunya adalah banyaknya keluhan pasien terhadap pelayanan BPJS Kesehatan di rumah sakit dikarenakan minimnya sosialisasi mengenai alur rujukan dan prosedur administratif untuk berobat lebih lanjut (Handini, 2015). Selain itu, masalah lain yang muncul adalah terkait peningkatan jumlah pasien yang tidak diimbangi dengan pelayanan yang diberikan oleh pelayanan kesehatan yang bekerja sama dengan BPJS Kesehatan. Hal tersebut tentu dapat berdampak pada kepuasan pasien. Kepuasan pasien menjadi hal yang sangat penting bagi sebuah rumah sakit karena kepuasan pasien merupakan salah satu indikator yang dinilai dalam standar pelayanan minimal rumah sakit. Selain itu, kepuasan pasien juga merupakan indikator kualitas pelayanan yang diberikan oleh rumah sakit.

Unit Pelaksana Teknis Rumah Sakit Mata Masyarakat Jawa Timur merupakan rumah sakit milik Pemerintah Provinsi Jawa Timur yang secara khusus menyediakan pelayanan kesehatan mata dan merupakan salah satu rumah sakit yang bekerja sama dengan BPJS Kesehatan. Studi pendahuluan dilakukan untuk mengetahui kepuasan pasien di Instalasi Rawat Jalan UPT RSMM Jawa Timur dengan metode wawancara kepada 50 pasien, baik pasien dengan pembayaran menggunakan kartu BPJS Kesehatan maupun pasien dengan pembayaran umum. Studi pendahuluan dilakukan pada bulan Januari tahun 2017.

Berdasarkan hasil studi pendahuluan, diketahui bahwa sebesar $72 \%$ atau 36 pasien merasa puas dan $28 \%$ atau 14 pasien tidak merasa puas terhadap pelayanan UPT RSMM Jawa Timur. Hal tersebut menunjukkan bahwa kepuasan pasien di Instalasi Rawat Jalan UPT RSMM Jawa Timur belum 
memenuhi Standar Pelayanan Minimal yang ditetapkan oleh Kepmenkes No. 129 tahun 2008 tentang Standar Pelayanan Minimal Rumah Sakit yaitu kepuasan pasien rawat jalan $\geq 90 \%$.

Menurut Cadotte dkk (1987) kepuasan pelanggan adalah perasaan yang timbul sebagai hasil evaluasi terhadap pengalaman pemakaian dari suatu produk atau jasa. Strasser (1991) mendefinisikan bahwa kepuasan pasien adalah penilaian pasien dan reaksi selanjutnya terhadap stimuli yang didapatkan pada lingkungan pelayanan kesehatan baik sebelum, selama, maupun sesudah pasien rawat jalan maupun rawat inap mendapatkan pelayanan. Hal tersebut dipengaruhi oleh karakter disposisi pasien dan pengalaman pasien terhadap pelayanan kesehatan.

Salah satu faktor penyebab ketidakpuasan pasien adalah penilaian pasien terhadap service convenience. Menurut Berry dkk (2002) saat ini, convenience atau kenyamanan merupakan hal yang terpenting dalam diri konsumen. Selain itu, kepuasan merupakan salah satu bentuk dari service evaluation pada penilaian yang dilakukan oleh konsumen terhadap service convenience. Tjiptono (2004) berpendapat bahwa penilaian terhadap service convenience dapat berpengaruh terhadap evaluasi secara keseluruhan konsumen terhadap jasa yang telah didapatkan. Evaluasi tersebut meliputi kepuasan konsumen terhadap jasa, keadilan, dan kualitas jasa. Kondisi tersebut tentu membuat penyedia layanan mulai menyadari bahwa kebutuhan untuk membuat jasa yang ditawarkan menjadi senyaman mungkin adalah suatu hal yang penting. Hal tersebut diperkuat oleh penelitian yang dilakukan oleh Seiders dkk (2000) dan Colwell dkk (2008) yang mendapatkan hasil bahwa service convenience secara langsung dapat memengaruhi kepuasan konsumen sehingga apabila penyedia jasa ingin meningkatkan kepuasan konsumen, maka penyedia jasa harus meningkatkan service convenience.
Service convenience adalah persepsi individu mengenai waktu dan usaha yang berkaitan dengan pembelian atau pemakaian jasa yang ditawarkan (Berry dkk., 2002). Menurut Sumarno dkk (2016), service convenience merupakan salah satu strategi sebuah perusahaan untuk memenuhi kebutuhan konsumen dalam hal minimalisasi waktu dan usaha konsumen untuk mendapatkan manfaat terkait produk atau jasa yang ditawarkan sehingga pada akhirnya timbul kepuasan dan kepercayaan konsumen untuk kembali melakukan pembelian produk atau jasa yang ditawarkan. Menurut Kim dkk (2014), service convenience juga merupakan salah satu cara yang dapat dilakukan oleh perusahaan untuk dapat meningkatkan nilai pelanggan.

Berry dkk (2002) dan Colwell dkk (2008) mengemukakan bahwa service convenience sebagai konstruksi multidimensional yang disusun dari lima jenis service convenience yang meliputi, decision convenience, access convenience, transaction convenience, benefit convenience, dan postbenefit convenience.

Menurut Gupta dan Sharma (2014) lima jenis service convenience yang dikemukakan oleh Berry dkk (2002) tersebut berbasis pada lima tahap pembelian yang dialami oleh konsumen selama proses pembelian berdasarkan tahap pembelian yang dikemukakan oleh Engel dan Blackwell (1982). Chen dkk (2011) menyatakan bahwa lima jenis service convenience tersebut mendominasi kepuasan konsumen terhadap pelayanan jasa yang artinya semakin baik penilaian konsumen terhadap service convenience, maka konsumen akan semakin puas terhadap jasa tersebut.

Oleh karena itu, tujuan dari penelitian ini adalah untuk menganalisis service convenience UPT RSMM Jawa Timur yang meliputi decision convenience, access convenience, transaction convenience, benefit convenience, dan postbenefit convenience. 


\section{METODE PENELITIAN}

Penelitian ini merupakan penelitian deskriptif dengan rancang bangun cross sectional. Populasi dalam penelitian ini adalah seluruh pasien pada Instalasi Rawat Jalan UPT RSMM Jawa Timur. Berdasarkan data internal UPT RSMM Jawa Timur, jumlah kunjungan pasien pada Instalasi Rawat Jalan UPT RSMM Jawa Timur pada tahun 2016 berjumlah 55.338 kunjungan. Penentuan besar populasi didasarkan pada data tersebut, sehingga dalam satu bulan diasumsikan bahwa rata-rata kunjungan pasien adalah sebanyak 4.612 kunjungan. Perhitungan sampel dilakukan dengan menggunakan rumus Lemeshow (1991) sehingga didapatkan besar sampel sebanyak 72 responden.

Teknik pengambilan sampel dilakukan dengan non probability sampling yaitu dengan accidental sampling. Adapun pasien yang dapat menjadi responden dalam penelitian ini adalah pasien dengan kriteria sebagai berikut; 1) pasien telah selesai mendapatkan pelayanan pada Instalasi Rawat Jalan UPT RSMM Jawa Timur, 2) berusia $\geq 18$ tahun, 3) pasien dalam keadaan sadar dan mampu berkomunikasi dengan baik, bersedia diwawancarai atau mengisi kuesioner yang telah disediakan, 4) dan bukan merupakan pasien yang baru saja selesai melakukan operasi mata.

Penelitian dilaksanakan di Instalasi Rawat Jalan UPT RSMM Jawa Timur pada bulan Juni 2017. Variabel yang diteliti pada penelitian ini adalah service convenience yang meliputi decision convenience, access convenience, benefit convenience, dan postbenefit convenience

Instrumen pengumpulan data yang digunakan adalah kuesioner. Setelah data primer terkumpul, dilakukan pengolahan data menggunakan bantuan software statistik dan aplikasi komputer. Setelah itu, dilakukan analisis data dengan menggunakan analisis univariat yang bertujuan untuk mengetahui distribusi frekuensi dari masing-masing variabel dalam penelitian ini dengan melakukan scoring dan kategori hasil dari pengukuran kuesioner. Langkah berikutnya adalah menyimpulkan hasil kategori tersebut berdasarkan prinsip Pareto, yaitu dinilai tingkat kategori per variabel. Penilaian responden masih kurang baik apabila yang termasuk dalam kategori baik dan sangat baik kurang dari $80 \%$ sedangkan apabila kategori baik dan sangat baik mencapai $80 \%$ atau lebih maka penilaian responden terhadap variabel tersebut tergolong baik.

\section{HASIL}

\section{Karakteristik Responden}

Menurut Sangadji \& Sopiah (2013) karakteristik individu merupakan ciri-ciri atau kekhasan individu yang membedakan individu yang satu dengan yang lain. Adapun karakteristik responden dalam penelitian ini meliputi umur, jenis kelamin, dan pekerjaan.

Berdasarkan Tabel 1, diketahui bahwa mayoritas responden berjenis kelamin perempuan yaitu sebesar $65,3 \%$

Tabel 1. Distribusi Frekuensi Karakteristik Pasien di Instalasi Rawat Jalan UPT RSMM Jawa Timur Tahun 2017

\begin{tabular}{lcc}
\hline $\begin{array}{c}\text { Karakteristik } \\
\text { responden }\end{array}$ & Frekuensi & Persen (\%) \\
\hline $\begin{array}{l}\text { Jenis Kelamin } \\
\text { Laki-Laki }\end{array}$ & 25 & $34,7 \%$ \\
Perempuan & 47 & $65,3 \%$ \\
\hline Total & 72 & $100 \%$ \\
\hline Umur & & \\
$<25$ tahun & 3 & $4,2 \%$ \\
$26-45$ tahun & 15 & $20,8 \%$ \\
$46-65$ tahun & 37 & $51,4 \%$ \\
$>65$ tahun & 17 & $23,6 \%$ \\
\hline Total & 72 & $100,0 \%$ \\
\hline Status pekerjaan & & \\
Bekerja & 50 & $69,4 \%$ \\
Tidak bekerja & 22 & $30,6 \%$ \\
\hline Total & 72 & $100 \%$ \\
\hline
\end{tabular}


atau sebanyak 47 responden. Mayoritas responden berumur 46-65 tahun yang termasuk ke dalam kelompok umur lansia yaitu sebanyak 37 responden $(51,4 \%)$, dan mayoritas responden yaitu sebesar $51,4 \%$ atau sebanyak 37 responden tidak bekerja.

\section{Service Convenience}

Penilaian mengenai service convenience UPT RSMM Jawa Timur didapatkan melalui variabel service convenience yang meliputi decision convenience, access convenience, transaction convenience, benefit convenience, dan postbenefit convenience. Berikut merupakan hasil dari perhitungan masing-masing variabel

\section{Decision Convenience}

Tabel 2. Distribusi Penilaian Decision Convenience Pasien Instalasi Rawat Jalan UPT RSMM Jawa Timur Tahun 2017

\begin{tabular}{lcc}
\hline $\begin{array}{c}\text { Decision } \\
\text { Convenience }\end{array}$ & $\begin{array}{c}\text { Jumlah } \\
\text { (orang) }\end{array}$ & Persentase (\%) \\
\hline Tidak Baik & 1 & $1,4 \%$ \\
Kurang Baik & 3 & $4,2 \%$ \\
Baik & 35 & $48,6 \%$ \\
Sangat Baik & 33 & $45,8 \%$ \\
\hline Total & 72 & $100,0 \%$ \\
\hline
\end{tabular}

Berry dkk (2002) menjelaskan bahwa decision convenience adalah persepsi konsumen terkait waktu dan usaha serta hal-hal yang dapat membuat konsumen melakukan keputusan pembelian atau memakai jasa yang ditawarkan.

Berdasarkan Tabel 2, diketahui bahwa sebagian besar $(94,1 \%)$ responden memiliki penilaian yang baik dan sangat baik terhadap decision convenience UPT RSMM Jawa Timur. Menurut Chinchuluun dkk (2008) dalam prinsip pareto terdapat aturan $80 / 20$ yang berarti $80 \%$ masalah disebabkan karena $20 \%$ penyebab. Berdasarkan prinsip tersebut dapat disimpulkan bahwa decision convenience UPT RSMM Jawa Timur sudah dalam kategori baik.

\section{Access Convenience}

Tabel 3. Distribusi Penilaian Access Convenience Pasien Instalasi Rawat Jalan UPT RSMM Jawa Timur Tahun 2017

\begin{tabular}{lcc}
\hline $\begin{array}{c}\text { Access } \\
\text { Convenience }\end{array}$ & $\begin{array}{c}\text { Jumlah } \\
\text { (orang) }\end{array}$ & Persentase (\%) \\
\hline Tidak baik & 4 & $5,6 \%$ \\
Kurang baik & 23 & $31,9 \%$ \\
Baik & 31 & $43,1 \%$ \\
Sangat Baik & 14 & $19,4 \%$ \\
\hline Total & 72 & $100,0 \%$ \\
\hline
\end{tabular}

Access convenience adalah persepsi konsumen terkait waktu dan usaha untuk menginisiasi penyampaian jasa yang meliputi tindakan-tindakan yang harus dilakukan oleh konsumen untuk membeli jasa tersebut (Berry dkk, 2002).

Berdasarkan Tabel 3, diketahui bahwa sebagian besar $(62,5 \%)$ responden memiliki penilaian yang baik dan sangat baik terhadap access convenience UPT RSMM Jawa Timur. Berdasarkan prinsip pareto, dapat disimpulkan bahwa access convenience UPT RSMM Jawa Timur masih dalam kategori kurang baik dikarenakan persentase penilaian responden yang termasuk ke dalam kategori baik dan sangat baik masih dibawah $80 \%$.

\section{Transaction Convenience}

Tabel 4. Distribusi Penilaian Transaction Convenience Pasien Instalasi Rawat Jalan UPT RSMM Jawa Timur Tahun 2017

\begin{tabular}{lcc}
\hline $\begin{array}{c}\text { Transaction } \\
\text { Convenience }\end{array}$ & $\begin{array}{c}\text { Jumlah } \\
\text { (orang) }\end{array}$ & Persentase (\%) \\
\hline Kurang Baik & 24 & $33,3 \%$ \\
Baik & 39 & $54,2 \%$ \\
Sangat Baik & 9 & $12,5 \%$ \\
\hline Total & 72 & $100,0 \%$ \\
\hline
\end{tabular}


Berry dkk (2002) menjelaskan bahwa transaction convenience adalah persepsi konsumen terkait waktu dan usaha untuk mengadakan sebuah transaksi. Tipe kenyamanan ini berfokus pada tindakantindakan yang harus dilakukan konsumen untuk mendapatkan hak atas pemakaian jasa yang ditawarkan.

Berdasarkan Tabel 4, diketahui bahwa mayoritas responden yaitu sebesar $66,7 \%$ responden memiliki penilaian yang baik dan sangat baik terhadap transaction convenience UPT RSMM Jawa Timur. Chinchuluun dkk (2008) menyatakan bahwa dalam prinsip pareto, $80 \%$ masalah disebabkan karena $20 \%$ penyebab. Hal tersebut menunjukkan bahwa transaction convenience masih termasuk ke dalam kategori kurang baik karena persentase masih dibawah $80 \%$ sehingga masih perlu mendapatkan perhatian dari UPT RSMM Jawa Timur.

\section{Benefit Convenience}

Benefit Convenience adalah persepsi konsumen mengenai waktu dan usaha untuk mendapatkan manfaat inti dari jasa yang ditawarkan (Berry dkk, 2002).

Tabel 5. Distribusi Penilaian Benefit Convenience Pasien Instalasi Rawat Jalan UPT RSMM Jawa Timur Tahun 2017

\begin{tabular}{lcc}
\hline $\begin{array}{c}\text { Benefit } \\
\text { Convenience }\end{array}$ & $\begin{array}{c}\text { Jumlah } \\
\text { (orang) }\end{array}$ & Persentase (\%) \\
\hline Kurang Baik & 1 & $1,4 \%$ \\
Baik & 44 & $61,1 \%$ \\
Sangat Baik & 27 & $37,5 \%$ \\
\hline Total & 72 & $100,00 \%$ \\
\hline
\end{tabular}

Berdasarkan Tabel 5, diketahui bahwa sebagian besar $(98,6 \%)$ responden memiliki penilaian yang baik dan sangat baik terhadap benefit convenience UPT RSMM Jawa Timur. berdasarkan prinsip pareto, hasil tersebut sudah termasuk ke dalam kategori baik karena persentase responden yang termasuk ke dalam kategori baik dan sangat baik sudah diatas $80 \%$.

\section{Postbenefit Convenience}

Tabel 6. Distribusi Penilaian Postbenefit Convenience Pasien Instalasi Rawat Jalan UPT RSMM Jawa Timur Tahun 2017

\begin{tabular}{lcc}
\hline $\begin{array}{c}\text { Postbenefit } \\
\text { Convenience }\end{array}$ & $\begin{array}{c}\text { Jumlah } \\
\text { (orang) }\end{array}$ & Persentase (\%) \\
\hline Kurang Baik & 3 & $4,2 \%$ \\
Baik & 35 & $48,6 \%$ \\
Sangat Baik & 34 & $47,2 \%$ \\
\hline Total & 72 & $100,00 \%$ \\
\hline
\end{tabular}

Menurut Berry dkk (2002) postbenefit convenience adalah persepsi konsumen terkait waktu dan usaha untuk menghubungi kembali penyedia jasa setelah konsumen mendapatkan manfaat dari penggunaan jasa tersebut.

Berdasarkan Tabel 6, diketahui bahwa sebagian besar $(95,8 \%)$ responden memiliki penilaian yang baik dan sangat baik terhadap postbenefit convenience UPT RSMM Jawa Timur. Hal tersebut menunjukkan bahwa postbenefit convenience sudah termasuk ke dalam kategori baik karena persentase penilaian responden yang termasuk ke dalam kategori baik dan sangat baik sudah berada diatas $80 \%$.

\section{PEMBAHASAN}

\section{Karakteristik Responden}

Umur responden dalam penelitian ini dikategorikan menjadi empat kelompok, yaitu kelompok umur muda apabila umur responden di bawah 25 tahun, kelompok umur dewasa dengan rentang umur 2645 tahun, kelompok umur lansia dengan rentang umur 46-65 tahun dan kelompok umur manula jika umur responden lebih dari 65 tahun. Pengelompokan umur tersebut berdasarkan pada Depkes RI (2009), dimana terdiri dari sembilan kategori umur yang kemudian disingkat menjadi empat kategori. Berdasarkan Tabel 1, diketahui bahwa mayoritas umur responden yaitu sebanyak 37 responden $(51,4 \%)$ berada pada kelompok 
umur lansia (46-65 tahun), dan paling sedikit yaitu sebanyak 3 responden $(4,2 \%)$ termasuk ke dalam kelompok umur muda ( $\leq 25$ tahun). Lebih banyaknya kelompok umur lansia jika dibandingkan dengan kelompok umur muda dikarenakan secara fisiologis tubuh individu yang sudah berumur tua kondisinya tidak seoptimal dengan individu yang berumur muda sehingga orang yang sudah berumur tua akan lebih sering memanfaatkan pelayanan kesehatan (Rahayu, 2011). Hal tersebut diperkuat dengan pernyataan Folland et al ., (2007) yang menyatakan bahwa perbedaan tingkat umur memengaruhi penggunaan pelayanan kesehatan. Orang yang berumur tua akan memanfaatkan pelayanan lebih banyak dibandingkan dengan seseorang yang berumur muda karena memiliki perbedaan risiko sakit.

Berdasarkan Tabel 1, diketahui bahwa mayoritas responden dalam penelitian ini adalah perempuan. Menurut Fuchs (1998) perempuan memiliki risiko sakit lebih tinggi jika dibandingkan dengan laki-laki. Hal tersebut tentunya dapat menyebabkan perempuan akan lebih sering memanfaatkan pelayanan kesehatan jika dibandingkan dengan laki-laki. Selain itu, angka kerja perempuan juga lebih rendah apabila dibandingkan dengan laki-laki sehingga perempuan tentunya memiliki banyak waktu untuk mengakses pelayanan kesehatan. Selain itu, perempuan lebih sering menggunakan pelayanan kesehatan karena perempuan lebih sering memeriksakan keadaannya apabila merasa sakit (Rahayu, 2011).

Berdasarkan Tabel 1, diketahui bahwa mayoritas responden yaitu sebanyak 51,4\% atau sebanyak 37 responden tidak bekerja. Lebih banyaknya responden yang tidak bekerja dibandingkan dengan responden yang bekerja disebabkan karena responden yang memiliki pekerjaan cenderung tidak memiliki waktu untuk pergi ke pelayanan kesehatan. Berdasarkan wawancara kepada salah satu responden yang bekerja, untuk dapat berobat di UPT RSMM Jawa Timur Ia harus mengatur waktu dan izin kepada atasan terlebih dahulu untuk dapat berobat.

\section{Decision Convenience}

Decision atau keputusan adalah suatu kesimpulan dari proses untuk memilih tindakan yang terbaik dari sejumlah alternatif yang ada (Siagian, 1997). Dalam tahap ini, ketersediaan dan kualitas informasi tentang penyedia layanan dan pesaing menentukan decision convenience konsumen (Sumarno $\mathrm{dkk}, 2016)$. Apabila penyedia jasa dapat memberikan informasi mengenai pelayanan yang disediakan dan membuat konsumen yakin bahwa pelayanan tersebut lebih baik jika dibandingkan dengan pesaing, maka konsumen akan memiliki decision convenience yang baik terhadap penyedia jasa tersebut. Hal tersebut dikarenakan apabila informasi mengenai pelayanan jasa semakin mudah diperoleh, maka konsumen akan semakin yakin terhadap kualitas dari pelayanan jasa tersebut sehingga konsumen akan semakin cepat untuk memutuskan pembelian terhadap jasa.

Berdasarkan hasil penelitian, diperoleh hasil bahwa penilaian responden terhadap decision convenience UPT RSMM Jawa Timur sudah tergolong baik. Walaupun decision convenience UPT RSMM Jawa Timur sudah termasuk kedalam kategori baik namun berdasarkan wawancara kepada responden, sebelum dirujuk oleh FKTP mayoritas belum mengetahui UPT RSMM Jawa Timur. Oleh karena itu, UPT RSMM Jawa Timur perlu memberikan informasi atau promosi yang lebih gencar lagi terkait pelayanan maupun fasilitas yang ada dan diunggulkan oleh UPT RSMM Jawa Timur melalui media maupun internet yang disesuaikan dengan segmentasi pasien. UPT RSMM Jawa Timur juga perlu berfokus pada penguatan merek karena dengan memiliki merek yang kuat, maka UPT RSMM Jawa Timur dapat menawarkan decision convenience kepada pasien.

Menurut Tjiptono (2004) apabila konsumen memiliki informasi yang banyak terhadap suatu penyedia jasa, maka konsumen akan lebih cepat dalam memutuskan untuk menggunakan atau membeli jasa 
tersebut sehingga dalam hal ini, penyedia jasa mampu membantu konsumen dalam menyederhanakan proses pemilihan jasa. Selain itu, keputusan dan kemudahan untuk memperoleh informasi merupakan hal yang paling penting sebelum terjadinya pertukaran layanan yang sebenarnya (Seiders dkk, 2000). Banyaknya pengetahuan maupun informasi yang dimiliki konsumen tentang produk atau jasa juga akan memengaruhi proses persepsi konsumen yang terbentuk dari sikap dan hal tersebut akan memengaruhi respon konsumen terhadap kepuasan (Scribner dan Weun, 2000).

\section{Access Convenience}

Menurut Wasisto (1990) akses atau keterjangkauan adalah kemudahan pelayanan yang ditinjau dari lokasi geografi dan jam pelayanan suatu jasa. Lokasi yang mudah dijangkau, aman, dan kemudahan transportasi menuju unit pelayanan tersebut tentunya dapat memengaruhi pelanggan untuk dapat berobat ke unit pelayanan tersebut (Mauludiani, 2005). Pelayanan kesehatan dikatakan strategis apabila mudah dicapai oleh masyarakat dari sudut lokasi (Rahayu, 2011).

Berdasarkan hasil penelitian, diperoleh hasil bahwa penilaian responden terhadap access convenience UPT RSMM Jawa Timur masih tergolong kurang baik karena persentase penilaian responden yang termasuk ke dalam kategori baik dan sangat baik masih di bawah $80 \%$. Dalam penelitian ini, aspek terkait access convenience yang memperoleh penilaian paling rendah dari responden adalah aspek kemudahan lokasi UPT RSMM Jawa Timur untuk dijangkau karena sebanyak 16 responden $(22,2 \%)$ menilai bahwa lokasi UPT RSMM Jawa Timur sangat tidak strategis.

Berdasarkan komentar responden, lokasi UPT RSMM Jawa Timur tidak strategis karena tidak berada di dekat jalan sehingga tidak ada angkutan umum yang melintasi UPT RSMM Jawa Timur. Hal tersebut membuat responden yang tidak membawa kendaraan pribadi merasa kesulitan untuk menjangkau UPT RSMM Jawa Timur sehingga memerlukan biaya transportasi yang lebih untuk dapat berobat di UPT RSMM Jawa Timur. Walaupun begitu, mayoritas responden menyatakan tidak keberatan untuk menyediakan biaya lebih untuk transportasi menuju UPT RSMM Jawa Timur karena mereka berpendapat bahwa untuk kepentingan berobat mereka akan mengutamakannya. Menurut Maululdiani (2005) hal tersebut sesuai dengan teori bahwa opportunity cost dalam pelayanan kesehatan dapat diukur dengan baik dengan keuntungan kesehatan, misal angka harapan hidup dapat ditingkatkan dengan menghabiskan biaya untuk mendapatkan pelayanan kesehatan yang baik.

Berdasarkan sejarahnya, UPT RSMM Jawa Timur pada awalnya berlokasi di Jl. Indrapura No. 17. Namun, dikarenakan bangunan UPT RSMM Jawa Timur yang lama masih berstatus menumpang bangunan milik Pusat Penelitian Pengembangan Pelayanan dan Teknologi Kesehatan dan tidak memungkinkan untuk dikembangkan menjadi Pusat Rujukan Pelayanan Kesehatan Mata se-Jawa Timur sesuai dengan visi UPT RSMM Jawa Timur maka bangunan UPT RSMM Jawa Timur mengalami relokasi ke Jl. Gayung Kebonsari Timur No. 49. Sebelumnya, UPT RSMM Jawa Timur berkeinginan untuk relokasi di daerah Jembatan Merah karena masih merupakan jalur ramai dan masih dekat dengan lokasi UPT RSMM Jawa Timur yang lama namun dikarenakan Pemerintah Provinsi Jawa Timur tidak memiliki aset di daerah tersebut, maka UPT RSMM Jawa Timur di relokasi di Jl. Gayung Kebonsari Timur. Selain itu, sebelum di relokasi telah dilakukan survei kepada masyarakat sekitar J1. Gayung Kebonsari Timur terkait UPT RSMM Jawa Timur dan memperoleh hasil yang positif dari masyarakat sekitar.

Penelitian yang dilakukan oleh Mauludiani (2005) memperoleh hasil bahwa letak UPT RSMM Jawa Timur yang 
berlokasi di Jl. Gayung Kebonsari Timur No. 49 kurang tepat. Ketidaktepatan lokasi tersebut dapat menimbulkan kerugian sosial yang terdiri dari kerugian materi yang berupa waktu dan biaya dan kerugian non materi yang berupa kesulitan transportasi.

Rekomendasi yang dapat diberikan untuk meningkatkan access convenience UPT RSMM Jawa Timur adalah sebagai berikut, 1) UPT RSMM Jawa Timur perlu melakukan sosialisasi dan advokasi kepada pemerintah untuk melakukan pembuatan trayek baru angkutan umum yang melintasi UPT RSMM Jawa Timur, 2) UPT RSMM Jawa Timur perlu memberikan denah atau petunjuk arah yang jelas pada jalur yang strategis terkait lokasi guna memudahkan dalam pemberian informasi, 3) UPT RSMM Jawa Timur perlu mempertimbangkan untuk mengadakan fasilitas rumah singgah bagi pasien yang berasal dari luar kota Surabaya.

\section{Transaction Convenience}

Transaction convenience adalah persepsi konsumen terkait waktu dan usaha untuk mengadakan sebuah transaksi (Berry dkk, 2002). Convenience dalam konteks dimensi waktu ialah kemudahan mendapatkan pelayanan, dimensi tempat, dimensi prosedur yang diartikan kemudahan mendapatkan pelayanan secara cepat dan tidak berbelit belit (Supriyanto dan Wulandari, 2010). Tipe kenyamanan ini berfokus pada tindakan-tindakan yang harus dilakukan oleh konsumen untuk mendapatkan hak atas pemakaian jasa yang ditawarkan. Ketika konsumen telah memutuskan untuk membeli sebuah layanan dan telah mencapai lokasi layanan tersebut, konsumen tetap harus berpartisipasi dalam sebuah transaksi pada layanan tersebut (Tjiptono, 2004).

Berdasarkan hasil penelitian, diperoleh hasil bahwa penilaian responden terhadap transaction convenience UPT RSMM Jawa Timur masih tergolong kurang baik karena persentase penilaian responden yang termasuk ke dalam kategori baik dan sangat baik masih di bawah $80 \%$.
Dalam penelitian ini, transaction convenience diukur berdasarkan beberapa aspek diantaranya kemudahan alur pendaftaran, kecepatan waktu pendaftaran, kemudahan alur pelayanan, kecepatan untuk mendapatkan pelayanan dan kecepatan untuk menyelesaikan pelayanan. Adapun aspek yang memperoleh penilaian paling rendah dari responden adalah aspek kecepatan untuk mendapatkan pelayanan karena sebesar 29 responden (40,3\%) menilai bahwa kecepatan untuk mendapatkan pelayanan di UPT RSMM Jawa Timur sangat lama karena responden harus menunggu selama lebih dari 60 menit untuk mendapatkan pelayanan.

Berdasarkan hasil wawancara kepada responden, salah satu penyebab lamanya waktu tunggu untuk mendapatkan pelayanan dikarenakan pasien UPT RSMM Jawa Timur sangat banyak namun jumlah dokter yang menangani kurang memadai. Selain itu, semua pasien terlebih dahulu harus melakukan pemeriksaan di Poli 1 termasuk pasien anak. Walaupun pemeriksaan pasien anak dilakukan di Poli anak, namun pasien anak harus melalui Poli 1 terlebih dahulu untuk dibaca rekam medisnya.

Menurut Arietta (2011) menunggu merupakan hal yang tidak dapat dihindari di hampir semua pelayanan kesehatan karena tidak ada satupun penyedia layanan kesehatan yang mampu mempersiapkan diri secara sempurna untuk memberikan kebutuhan pasien sesaat setelah pasien tiba. Walaupun begitu, menunggu merupakan hal yang tidak disukai oleh pasien karena seperti yang diketahui bahwa orang yang dihadapi di rumah sakit merupakan orang yang sedang sakit sehingga emosinya menjadi labil dan tegang. Waktu tunggu pelayanan yang cepat merupakan hal yang diinginkan oleh pasien, sehingga sebaiknya UPT RSMM Jawa Timur memperhatikan lamanya waktu tunggu pelayanan oleh pasien. Menurut penelitian Mardiana (2012) lamanya waktu tunggu di bawah 60 menit memberikan kepuasan 2,65 kali lebih puas daripada waktu tunggu diatas 60 menit. Oleh sebab itu, waktu tunggu yang 
semakin cepat akan meningkatkan kepuasan pasien.

Rekomendasi yang dapat diberikan untuk meningkatkan transaction convenience UPT RSMM Jawa Timur adalah sebagai berikut, 1) memaksimalkan penggunaan mesin EDC sebagai solusi untuk mempercepat dan memudahkan pasien dalam melakukan transaksi pembayaran, 2) mempertimbangkan agar pemeriksaan pada pasien anak dilakukan secara langsung pada Poli Anak sehingga pasien tidak perlu lagi ke Poli 1 agar lebih efisien, 3) melakukan survei mengenai waktu tunggu pasien untuk mendapatkan pelayanan setidaknya tiga bulan sekali untuk mengetahui lama waktu tunggu pasien.

\section{Benefit Convenience}

Seiders dkk (2007) menyatakan bahwa benefit convenience adalah dimensi yang paling berpengaruh terhadap service convenience. Apabila penyedia jasa dapat mengurangi biaya waktu dan usaha selama konsumen mendapatkan pelayanan terkait jasa tersebut maka konsumen akan memberikan penilaian yang baik terhadap benefit convenience kemudian konsumen akan memberikan reward terhadap penyedia jasa tersebut. Selain itu, Holden (2005) juga menyatakan bahwa keinginan untuk mendapatkan benefit dari suatu pelayanan jasa adalah alasan awal konsumen memilih sebuah pelayanan jasa sehingga sangat penting untuk dilakukan evaluasi terhadap layanan yang diberikan oleh penyedia jasa. Apabila dalam tahap ini konsumen merasakan mendapatkan manfaat, maka akan tercipta hubungan jangka panjang yang menguntungkan dalam hal waktu, usaha dan kemudahan sehingga penyedia jasa harus memberikan penekanan eksplisit pada aspekaspek ini mulai dari prosedur, proses dan interaksi bagi konsumen (Ludiya, 2010).

Berdasarkan penelitian, didapatkan hasil bahwa penilaian pasien terhadap benefit convenience UPT RSMM Jawa Timur sudah tergolong baik karena persentase sudah berada di atas $80 \%$.
Walaupun penilaian responden terhadap benefit convenience sudah baik, namun layanan merupakan salah satu proses penting dalam meningkatkan value dari sebuah organisasi sehingga nilai layanan yang tercipta harus selalu dikelola secara terus menerus tidak hanya saat melakukan pendekatan kepada pelanggan pada saat transaksi, tapi juga setelah pelayanan selesai agar salah satu misi UPT RSMM Jawa Timur yaitu menyelenggarakan pelayanan kesehatan mata yang bermutu, efektif, efisien secara paripurna dalam mengatasi masalah kesehatan mata masyarakat dapat tercapai (Kartajaya, 2009).

\section{Postbenefit Convenience}

Menurut Berry dkk (2002) postbenefit convenience adalah persepsi konsumen terkait waktu dan usaha untuk menghubungi kembali penyedia jasa setelah tahap manfaat jasa. Tipe convenience ini berhubungan dengan kebutuhan pelanggan termasuk situasi ketika seorang pasien harus melakukan follow up appointment untuk keperluan evaluasi pasca operasi (Tjiptono, 2004). Salah satu cara untuk meningkatkan postbenefit convenience pelayanan kesehatan adalah dengan mengingatkan waktu berobat kembali dan komunikasi mengenai perkembangan kesehatan pasien secara langsung atau tidak langsung (via telepon atau internet) karena komunikasi yang terjalin baik menumbuhkan rasa percaya pasien terhadap rumah sakit (Crisnayanti, 2014).

Berdasarkan hasil penelitian, diketahui bahwa postbenefit convenience UPT RSMM Jawa Timur sudah dalam kategori baik. Mayoritas responden yaitu sebesar 33 responden $(45,8 \%)$ menilai bahwa dokter UPT RSMM Jawa Timur sudah sangat jelas dalam memberikan jadwal kontrol. Pemberian jadwal kontrol tersebut membuat responden berpendapat bahwa mereka tidak memerlukan banyak usaha untuk mengatur layanan lanjutan setelah berobat. Namun, dokter harus memberikan pemahaman mengenai kontrol secara lebih mendalam 
kepada pasien dikarenakan berdasarkan wawancara, diketahui bahwa masih ada pasien yang merasa kebingungan terkait kontrol karena dokter tidak memberikan pemahaman secara lebih lanjut. Dalam tahap ini, komunikasi antara dokter dengan pasien merupakan hal yang paling penting dikarenakan dengan adanya komunikasi yang baik yang meliputi pemberian perhatian kepada pasien, dan memberikan jasa serta pemahaman terhadap pelanggan merupakan kunci dari terciptanya hubungan yang intens antara pasien dengan UPT RSMM Jawa Timur selaku penyedia jasa (Zeithaml dkk,1990).

\section{SIMPULAN}

Kesimpulan dari penelitian ini adalah mayoritas responden memberikan penilaian yang baik terhadap decision convenience, benefit convenience, dan postbenefit convenience UPT RSMM Jawa Timur. Akan tetapi, mayoritas responden memberikan penilaian yang kurang baik terhadap access convenience dan transaction convenience.

Saran bagi pihak UPT RSMM Jawa Timur adalah diharapkan dapat mempertimbangkan untuk mengadakan fasilitas rumah singgah bagi pasien luar kota, menambah baliho yang berisikan informasi mengenai lokasi, fasilitas dan pelayanan yang disediakan dan diunggulkan oleh UPT RSMM Jawa Timur yang diletakkan di tempat-tempat strategis, menambahkan papan petunjuk yang jelas terkait lokasi UPT RSMM Jawa Timur, mengadakan survei mengenai waktu tunggu pada pasien untuk mendapatkan pelayanan setidaknya tiga bulan sekali, dan memaksimalkan penggunaan mesin EDC dalam melakukan transaksi pembayaran guna mempermudah dan mempercepat transaksi.

\section{DAFTAR PUSTAKA}

Apriyanti, S. 2017. Analisis Hubungan Service Convenience dengan Kepuasan Pasien (Studi di Instalasi Rawat Jalan
UPT Rumah Sakit Mata Masyarakat Jawa Timur. Skripsi. Surabaya: Universitas Airlangga.

Arietta, R.R., 2011. Analisis Waktu Tunggu Pasien di Departemen Gigi dan Mulut RSPAD Gatot Soebroto DITKESAD Tahun 2011. Tesis. Depok: Universitas Indonesia. Tersedia di http://lib.ui.ac. $\mathrm{id} /$ file?file=digital/20315207-T31807Analisis\%20waktu.pdf [21 Juli 2017].

Berry, L.L., Seiders, K., Grewal, D., 2002. Understanding Service Convenience. Journal of Marketing, 66(03): pp.1-17. Tersedia di http://www.dhruvgrewal.com/ wp-content/uploads/2014/09/2002-JMSERVICE-CONVENIENCE-MODEL. pdf [1 April 2017].

Cadotte, E.R. Woodruff, R.B. Jenkins, R.L. 1987. Expectations and Norms in Models of Consumer Satisfaction. Journal of Marketing Research, 25, 305-314.

Chen, M.C., Chang, K.C., Hsu., C.L., dan Yang, I.C., 2011. Understanding The Relationship Between Service Convenience And Customer Satisfaction In Home Delivery By Kano Model. Asia Pacific Journal of Marketing and Logistics, 23(3): pp. 386-410. Tersedia di: www.emeraldinsight.com/1355-5855.htm [3 April 2017].

Chinchuluun, A., Pardalos, P. M., Migdalas, A. and Pitsoulis, L., 2008. Pareto Optimality, Game Theory And Equilibria. New York: Springer.

Colwell, S.R., Aung, M., Kanetkar, V., Holden, A.L., 2008. Toward A Measure Of Service Convenience: Multiple-Item Scale Development And Empirical Test. Journal of Services Marketing, 22(02): pp.160-169. Tersedia di http://www.emeraldinsight.com/doi/ abs/10.1108/08876040810862895 [20 Juli 2017].

Crisnayanti, P., 2014. Pengaruh Service Convenience terhadap Loyalitas Pasien Poliklinik Cendana RSUP Dr. Soeradji Tirtonegoro Klaten. Tesis. Yogyakarta: 
Universitas Muhammadiyah Yogyakarta. http://thesis.umy.ac.id/datapublik/t30131. pdf [20 Juli 2017].

Departemen Kesehatan. 2009. Profil Kesehatan Indonesia. Jakarta: Departemen Kesehatan Republik Indonesia.

Folland, S., Allen C.G., Miron, S., 2007. The Economics of Health and Healthcare Sixth Edition. New Jersey: Prentice Hall

Fuchs, V.R. 1998. Managing Quality: The Strategic and Competitive Edge. New York: The Free Pass.

Gupta, S., Sharma, D., 2014. Dimensions Of Retail Service Convenience In Emerging Market Settings -A Qualitative Investigation. Journal of Services Research, 14(01): pp.100-122. Tersedia di https://www.researchgate.net/ publication/313633990_DIMENSIONS O F R E T A I L S E R V I C E CONVENIENCE_IN_EMERGING_M A R K E T S E T T I N G S - A QUALITATIVE_INVESTIGATION $[2 \overline{0}$ Juli 2017].

Handini, I.P. 2015. Analisis Faktor yang Berhubungan dengan Pelayanan yang Diharapkan (Expected Service) dan Pelayanan yang Diterima (Perceived Service) Pasien (Studi di BPJS Kesehatan Center RSAL dr. Ramelan Surabaya). Skripsi. Surabaya: Universitas Airlangga.

Holden, A.L. 2005. Service Convenience Scale Development And The Examination of Its Impact on Service Provider Satisfaction. Thesis. University of Guelph. Tersedia di https://search.proquest.com/docview $/ 305001081$ ? accountid=50637 [21 Juli 2017].

Kartajaya, H. 2009. Service Operation. Jakarta: MarkPlus Institute of Marketing.

Kepmenkes No. 129 tahun 2008 Tentang Standar Pelayanan Minimal Rumah Sakit.

Kim, Y.K., Lee, M.Y., Park, S.H., 2014, Shopping Value Orientation: Conceptualization and Measurement, Journal of Business Research, 67 (1):pp.
2884-2890. Tersedia di http://www. sciencedirect.com/science/article/pii/ S0148296312001841 [22 Juli 2017].

Ludiya, H. 2010. Pengaruh Relational Benefits Terhadap Relational Outcomes Behavioral (WOM, Trust \& Commitment) Melalui Satisfaction (Survei Pada Nasabah Pt. Bank Negara Indonesia Wilayah Jakarta). Jurnal Manajemen Dan Pemasaran Jasa (Online), 3:pp. 77 96. Tersedia di: https://media.neliti.com/ media/publications/52563-ID-pengaruhrelational-benefits-terhadap-re.pdf [20 Juli 2017].

Mardiana, S. 2012. Analisis Kepuasan Pasien Terhadap Pelayanan Dokter Spesialis Penyakit Dalam di Instalasi Rawat Jalan RSUP Persahabatan Tahun 2012. Tesis. Depok: Universitas Indonesia. Tersedia di http://lib.ui.ac. $\mathrm{id} /$ file? file $=$ digital/20313145-T31236Analisis\%20kepuasan.pdf [20 Juli 2017].

Maululdiani, F. 2005. Analisis Letak Strategis Balai Kesehatan Mata Masyarakat (BKMM) di Kota Surabaya dengan Teori Analisis Pendekatan Pusat Gravitasi Sebagai Dasar Menentukan Kerugian Sosial. Tesis. Surabaya: Universitas Airlangga.

Rahayu, H.K. 2011. Analisis Hubungan Kualitas Pelayanan dengan Kepuasan Pasien di Puskesmas Ber-ISO 9001:2008. Skripsi. Surabaya: Universitas Airlangga.

Sangadji, E.M., Sopiah, 2013. Perilaku Konsumen; Pendekatan Praktis Disertai Himpunan Jurnal Penelitian.Yogyakarta: Andi.

Scribner, L.L., Weun, S., 2000. Understanding Consumer's Subjective Product Knowledge: A Theoretical Investigation. American Marketing Association. Conference Proceedings.

Seiders, K., Berry, L.L., Gresham, L.G., 2000. Attention Retailers: How Convenient Is Your Convenience Strategy?. Sloan Management Review, 49(3): pp.79-90. 
Seiders, et al 2007. SERVCON: Development And Validation Of A Multidimensional Service Convenience Scale. Journal of Academy Marketing Science, 35: pp. 144156. Tersedia di http://www.dhruvgrewal. com/wp-content/uploads/2014/09/2007JAMS-Conv.pdf [23 Juli 2017].

Siagian, P.S. 1997. Filsafat Administrasi. Jakarta: PT Toko Gunung Agung.

Sumarno, Soesanti, H., Sufian, S., 2016. Studi Mengenai Keputusan Pembelian Dengan Pendekatan Service Encounter, Service Convenience Dan Product Knowledge Yang Dimediasi Oleh Purchase Intention Pada Bengkel Pt. Astra InternationalDaihatsu Sales Operation Semarang. Jurnal Sains Pemasaran Indonesia, XV (02): pp. 93-106. Tersedia di http:// ejournal.undip.ac.id/index.php/jspi/ article/viewFile/14072/10673 [23 Juli 2017].
Supriyanto, S., Wulandari, R.D., 2010. Manajemen Mutu Pelayanan Kesehatan. Surabaya: Health Advocacy.

Strasser, S., Davis R.M., 1991. Measuring Patient Satisfaction for Improved Patient Service. Michigan: American College of Healthcare Executives.

Tjiptono, F. 2004. Pemasaran Jasa. Malang: Bayumedia Publishing.

Undang-Undang Republik Indonesia No. 36 Tahun 2009 Tentang Kesehatan.

Undang-Undang Republik Indonesia No. 40 Tahun 2004 Tentang Sistem Jaminan Sosial Nasional (SJSN).

Zeithaml, V.A., A. Parasuraman, dan L.L. Berry. 1990. Delivering Quality Service. New York: The Fee Press. 